\title{
The effect of radioiodine treatment on the characteristics of TRAb in Graves' disease
}

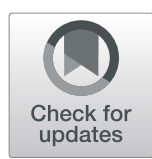

\author{
Ya Fang $^{1+}$, Wen-Hua Du ${ }^{2 \dagger}$, Cao-Xu Zhang ${ }^{1}$, Shuang-Xia Zhao ${ }^{1}$, Huai-Dong Song ${ }^{1 *}$, Guan-Qi Gao ${ }^{2^{*}}$ and Mei Dong ${ }^{\text {* }^{*}}$
}

\begin{abstract}
Background: Graves' disease (GD) is one of the most common autoimmune thyroid diseases (AITDs) in humans, and thyrotropin receptor antibody (TRAb) is a characterized autoantibody in GD. The use of radioactive iodine therapy (RAl) for GD treatment is increasing.

Objectives: We studied the biological properties of TRAb and evaluated the effect of RAl therapy on TRAb in GD patients.

Methods: In total, 225 patients (22 onset GD patients without ${ }^{131}$ | therapy, 203 GD patients treated with ${ }^{131}$ I therapy) and 20 healthy individuals as normal controls were included in this study. Clinical assessments were performed, and we examined in vitro the biological properties of TRAb in the 22 onset GD patients and 20 controls as well as $84 \mathrm{GD}$ patients with ${ }^{131}$ I therapy.

Results: Serum TRAb and thyroid peroxidase antibody (TPOAb) levels increased in the initial year of RAI treatment, and both antibodies decreased gradually after one year. After 5 years from radioiodine treatment, TRAb and TPOAb levels decreased in $88 \%$ and $65 \%$ of GD patients, respectively. The proportion of patients positive for thyroidstimulatory antibody (TSAb) was significantly higher in the 7-12-month group, and thyroid-blocking antibody (TBAb) levels were elevated after one year in half of the patients who received ${ }^{131}$ I treatment.

Conclusions: Treatment of GD patients with radioiodine increased TPOAb and TRAb (their main biological properties were TSAbs) within the first year after therapy, and the main biological properties of elevated TRAb were TBAbs after 1 year.
\end{abstract}

\section{Background}

Autoimmune thyroid diseases (AITDs), which primarily include Graves' disease (GD) and Hashimoto's thyroiditis (HT), are common organ-specific autoimmune diseases with varying severity and intractability [1]. AITDs are characterized by lymphocytic infiltration into the thyroid and the production of autoantibodies to thyroid-specific antigens, such as thyrotropin receptor (TSHR), thyroid

\footnotetext{
*Correspondence: huaidong_s1966@163.com; lygqgao@163.com; dm20180301@163.com

†Ya Fang and Wen-Hua Du are joint first authors.

${ }^{1}$ Department of Molecular Diagnostics \& Endocrinology, The Core Laboratory in Medical Center of Clinical Research, Shanghai Ninth People's Hospital, State Key Laboratory of Medical Genomics, Shanghai Jiao Tong University School of Medicine, 200011 Shanghai, China

2Department of Endocrinology, Linyi People's Hospital, Linyi, China
}

peroxidase (TPO) and thyroglobulin (Tg) [2-4]. The presence of thyrotropin receptor (TSHR) autoantibody (TRAb) is used in the serological diagnosis of GD [5]. TRAb has different biological properties, including thyroid-stimulatory antibodies (TSAbs), thyroid-blocking antibodies (TBAbs) and neutral TSH receptor antibodies $[6,7]$. Although a positive TRAb test result suggests the presence of TSAb or TBAb, it is reasonable to presume that a positive result in a patient with hyperthyroidism is due to TSAb. TSAb behaves like TSH and stimulates the synthesis of thyroid hormone by binding to TSHR, which leads to hyperthyroidism [8]. TSAb also causes diffuse, hypervascular goiter in many GD patients. However, some HT patients are TRAb positive, showing hypothyroidism rather than hyperthyroidism [9].

(c) The Author(s). 2021 Open Access This article is licensed under a Creative Commons Attribution 4.0 International License, which permits use, sharing, adaptation, distribution and reproduction in any medium or format, as long as you give appropriate credit to the original author(s) and the source, provide a link to the Creative Commons licence, and indicate if changes were made. The images or other third party material in this article are included in the article's Creative Commons licence, unless indicated otherwise in a credit line to the material. If material is not included in the article's Creative Commons licence and your intended use is not permitted by statutory regulation or exceeds the permitted use, you will need to obtain permission directly from the copyright holder. To view a copy of this licence, visit http://creativecommons.org/licenses/by/4.0/ The Creative Commons Public Domain Dedication waiver (http://creativecommons.org/publicdomain/zero/1.0/) applies to the data made available in this article, unless otherwise stated in a credit line to the data. 
Radioactive iodine therapy (RAI) is a beneficial choice for the treatment of patients with GD in some countries [10] because it is easy to administer, relatively inexpensive, safe and highly effective [11]. However, hypothyroidism is the main side effect of RAI treatment in patients with hyperthyroidism. TRAb decreases in some GD patients after RAI but increases in other patients. Such transient increases in TRAb levels in GD patients after the first several months from ${ }^{131}$ I treatment might be mediated by the release of thyroid antigens from damaged thyrocytes [12, 13]. Previous reports have found that GD patients with a significant increase in TSAb after 6 months from ${ }^{131} \mathrm{I}$ treatment develop hypothyroidism later [14]. This increase in TRAb can persist for many years in a few GD patients after ${ }^{131}$ I treatment, indicating that other factors that induce the production of TRAb exist.

The biological activities of TRAb may be assessed in vitro using cells transfected with TSH receptors that distinguish stimulating and blocking antibodies against TSHR [7]. The present study investigated patients with GD who received RAI and analyzed clinical changes in these patients after RAI therapy. We evaluated the biological properties of their TRAbs and assessed factors that may modulate the response. We also explored differences in the biological properties of TRAbs in the onset GD patients.

\section{Subjects and methods Subjects}

A total of 225 unrelated individuals with GD were recruited from Linyi People's Hospital and the Ninth People's Hospital Affiliated to Shanghai Jiao Tong University School of Medicine from May 2018 until August 2019. Among these 225 GD patients, 203 were treated with ${ }^{131}$ I therapy; the other 22 patients were diagnosed with GD onset and were not treated with ${ }^{131} \mathrm{I}$ therapy. The control group was composed of 20 unrelated healthy subjects from the same geographic region who were screened for thyroid autoimmune antibody (TRAb, TGAb and TPOAb) negative and had no family history of thyroid disease (age range from 26 to 58 years old and 9 females and 11 males). All of the subjects provided informed written consent, and the local ethics committee (the Ninth People's Hospital Affiliated to Shanghai Jiao Tong University School of Medicine) approved the project, which was performed in accordance with the ethical standards of the Declaration of Helsinki (2013 version) and its later amendments or comparable ethical standards. All cases conformed to the diagnostic and treatment criteria of thyroid disease in China (2007), which were compiled by experts from the Endocrinology Branch of the Chinese Medical Association [15, 16]. Diagnosis of GD was based on the principles described in our previous reports: clinical and biochemical manifestations of hyperthyroidism, diffuse goiter and at least one of the following phenotypes: positive TSH receptor antibody tests; diffusely increased ${ }^{131} \mathrm{I}$ (iodine-131) uptake in the thyroid gland or exophthalmos [17-19].

For the 203 GD patients treated with ${ }^{131} \mathrm{I}$, the following parameters were registered: age $(43.98 \pm 12.39$ years $)$, female/male sex $(n=172 / 31)$, duration of GD $(1.97 \pm$ 3.66 years), and treatment with corticosteroids $(n=13)$. The ${ }^{131} \mathrm{I}$ dose $(\mathrm{mCi})$ was equal to the thyroid mass $(\mathrm{g})$ multiplied by the ${ }^{131}$ I dose per gram thyroid tissue $(\mu \mathrm{Ci} /$ g) and divided by the 24-h maximal ${ }^{131} \mathrm{I}$ uptake rate $(8.59 \pm 3.23 \mathrm{mCi})$. The 22 untreated GD patients had a female:male ratio of $19: 3$, with an age range of $40.09 \pm$ 13.71 years. The control group of 20 healthy individuals had a female:male ratio of 9:11, with an age range of $42.20 \pm 15.87$ years, and had no history of autoimmune thyroid disease and normal values for TSH, FT3, FT4, TRAb and TPOAb. For the TSAb and TBAb subgroups, patients were selected randomly to ensure that those with different TRAb levels were chosen. Sera from subjects were collected by centrifuging whole blood at $2000 \mathrm{rpm}$ for $10 \mathrm{~min}$ and then heated at $56{ }^{\circ} \mathrm{C}$ for $30 \mathrm{~min}$ to remove complement. The samples were aliquoted and stored at $-80{ }^{\circ} \mathrm{C}$.

\section{Assays}

Serum FT3, FT4, TSH and TPOAb were detected using an Elecsys 2010 Chemiluminescence Immunoassay Analyzer (Roche, USA) and special auxiliary reagents (Roche, USA) according to the manufacturer's instructions. Serum TRAb was measured using the radiation receptor method with an assay kit (Union-med, China) [20]; the detection limit was 0.3 IU/L. The normal ranges of these parameters were FT3 (3.5-6.5 pmol/L), FT4 (11.5-22.7 pmol/L), TSH (0.55-4.78 $\mathrm{mIU} / \mathrm{L})$, TPOAb (0-60 IU/mL), and TRAb (0-1.75 IU/L).

TSHR-expressing Chinese hamster ovary $(\mathrm{CHO})$ cells were incubated with test serum or control serum. TSAb and TBAb levels were determined using a functional bioassay based on induction or inhibition of cAMP production. The cAMP concentration in transfected cells was measured using a cAMP assay kit (R\&D Systems assay, USA) [21]. Briefly, $4 \times 10^{4}$ stably transfected TSHR-CHO cells were seeded in 48-well plates. On the following day, the medium was removed, and the cells were incubated in Krebs-Ringer phosphate buffer (KRPB) for $15 \mathrm{~min}$ at $37{ }^{\circ} \mathrm{C}$. For stimulation experiments, the KRPB buffer was removed, and the cells were incubated in $100 \mu \mathrm{l}$ patient or control serum for another $2 \mathrm{~h}$ at $37{ }^{\circ} \mathrm{C}$. In blocking experiments, the KRPB buffer was removed, and the cells were incubated with $100 \mu \mathrm{l}$ patient or control serum with $1 \mathrm{IU} / \mathrm{L}$ bovine TSH (bTSH; Sigma Aldrich, USA) for $2 \mathrm{~h}$ at $37^{\circ} \mathrm{C}$. The cells were washed twice with cold PBS, lysates were prepared, 
and the cAMP concentration in the cells was measured as described in the instructions for the cAMP assay kit.

Activities of TSAb and TBAb were calculated as follows: TSAb activity (percent) $=100 \times($ cAMP patient $/$ cAMP control) and TBAb activity (percent) $=100 \times[1-$ (cAMP patient-bTSH/cAMP control-bTSH)].

\section{Statistical analysis}

Data were analyzed using SPSS 19.0 statistical software, and the results are presented as means \pm standard deviation. The normality of variables was estimated using the Kolmogorov-Smirnov test. One-way ANOVA was applied to detect multivariate significance. The MannWhitney $\mathrm{U}$ test, Welch's $\mathrm{t}$ test and Wilcoxon test were employed to compare significant differences between two groups, and $p<0.05$ was considered a statistically significant difference. Fold changes in antibodies were determined: a fold change of 1.1 or greater was considered an increase, an inverse ratio of 1.1 or greater was considered a decrease, and the remaining ratios were defined as unchanged.

\section{Results}

\section{Clinical characteristics of patients}

Our study enrolled 20 healthy individual controls, 22 onset GD patients without ${ }^{131}$ I therapy and 203 GD patients who received ${ }^{131}$ I therapy. Paired serum samples were collected from 203 GD patients before and after ${ }^{131}$ I therapy. The features of their thyroid function are provided in Tables 1 and 2. Among the 203 GD patients administered ${ }^{131} \mathrm{I}, 78$ received antithyroid drugs before the therapy. After radioiodine treatment, there were no significant differences between the GD patients treated with or without drugs with regard to the following characteristics: age, FT3, FT4, TSH, TPOAb and TRAb (data not shown). After ${ }^{131}$ I therapy, the overall average TRAb and TPOAb levels of the GD patients decreased significantly compared to the levels before RAI therapy
(Table 1). To assess RAI prognosis more accurately, the 203 GD patients were divided into 4 groups based on the treatment course after ${ }^{131}$ I therapy: 22 after $1-6$ months from ${ }^{131}$ I treatment, 28 after $7-12$ months from ${ }^{131}$ I treatment, 105 after $13-60$ months from ${ }^{131}$ I treatment and 48 after more than 60 months from ${ }^{131}$ I treatment. Among the four groups, we found no significant differences in the distribution of age, levels of FT4, TPOAb, or TRAb, ${ }^{131}$ I dose or 24-h maximal ${ }^{131}$ I uptake rate (\%) before ${ }^{131}$ I therapy. However, the TSH level baseline was the lowest in those after $7-12$ months from ${ }^{131}$ I therapy, compare to the other three groups (Table 2).

\section{The natural course of TRAb and TPOAb in GD patients after treatment with radioiodine}

To further investigate the natural course of TRAb and TPOAb in GD patients after treatment with ${ }^{131} \mathrm{I}$ therapy, we compared serum levels of TRAb and TPOAb before and after ${ }^{131}$ I radiotherapy in the above four groups. No significant differences in TRAb and TPOAb levels emerged comparing baseline data with those after 1-6 months from radioiodine treatment (Fig. 1A, B). After 7-12 months from ${ }^{131}$ I therapy, serum levels of TRAb increased significantly compared to data before radioiodine therapy (Fig. 1A). In the group of GD patients after 7-12 months from ${ }^{131}$ I therapy, no significant difference in TPOAb was detected compared with data before treatment with ${ }^{131} \mathrm{I}$ (Fig. 1B). Notably, serum levels of TPOAb and TRAb in the GD patients after $13-60$ months or over 60 months from ${ }^{131} \mathrm{I}$ therapy were significantly lower than those after 1-6 months from ${ }^{131}$ I therapy (Fig. 1A, B). We also found that levels of TRAb in $88 \%$ and TPOAb in $65 \%$ of GD patients decreased by more than 1.1 times after 5 years from they received radioiodine therapy (Table 3; Fig. 2).

\section{Biological characterization of TRAb}

To further investigate changes in TRAb after radioiodine treatment, we performed cell experiments to analyze the

Table 1 The clinical characteristics of patients with GD and normal controls

\begin{tabular}{llllll}
\hline Variable & Control group & Onset GD without ${ }^{\mathbf{1 3 1} \text { I therapy }}$ & GD before ${ }^{\mathbf{1 3 1} \text { I therapy }}$ & GD after ${ }^{\mathbf{1 3 1} \text { I therapy }}$ Normal range \\
\hline No. & 20 & 22 & 203 & & \\
Age(y) & $42.20 \pm 15.87$ & $40.09 \pm 13.71$ & $43.98 \pm 12.39$ & $31 / 172$ & \\
Gender(M/F) & $11 / 9$ & $3 / 19$ & $20.77 \pm 8.85$ & $4.46 \pm 1.32$ & $3.5-6.5$ \\
FT3(pmol/L) & $4.70 \pm 1.39$ & $21.17 \pm 9.62$ & $56.77 \pm 34.57$ & $15.27 \pm 7.47$ & $11.5-22.7$ \\
FT4(pmol/L) & $14.69 \pm 4.44$ & $64.48 \pm 44.15$ & $0.09 \pm 0.75$ & $12.95 \pm 24.65$ & $0.55-4.78$ \\
TSH(m/U/L) & $3.19 \pm 3.09$ & $0.002 \pm 0.001$ & $16.95 \pm 12.47^{* * *}$ & $10.14 \pm 13.30$ & $0-1.75$ \\
TRAb(IU/L) & $0.65 \pm 0.48$ & $11.28 \pm 10.17$ & $839.35 \pm 567.10^{\# \# \# \#}$ & $678.13 \pm 573.41$ & $0-60$ \\
TPOAb(IU/mL) & $29.44 \pm 4.30$ & $644.90 \pm 625.50$ & & &
\end{tabular}

Data are expressed as mean \pm standard deviation according to the distribution

$M$ male, $F$ female, GD Graves' disease

${ }^{* * *} p<0.001$ represents TRAb levels of GD before ${ }^{131}$ I therapy versus GD after ${ }^{131}$ I therapy

$\# \#$ \# $p .001$ represents TPOAb levels of GD before ${ }^{131} \mid$ therapy versus GD after ${ }^{131}$ I therapy 
Table 2 Comparison of clinical data before 1311 therapy between groups

\begin{tabular}{|c|c|c|c|c|}
\hline Group & 1-6 months & 7-12 months & $13-60$ months & $>60$ months \\
\hline Gender(M/F) & $6 / 16$ & $6 / 22$ & $12 / 93$ & $7 / 41$ \\
\hline Age(y) & $45.50 \pm 11.70$ & $38.86 \pm 11.96$ & $44.67 \pm 12.64$ & $44.77 \pm 11.67$ \\
\hline FT3(pmol/L) & $21.18 \pm 8.86$ & $25.05 \pm 6.35^{*}$ & $18.87 \pm 9.05^{*}$ & $22.18 \pm 8.38$ \\
\hline FT4(pmol/L) & $62.64 \pm 37.24$ & $64.02 \pm 35.42$ & $52.18 \pm 30.28$ & $63.41 \pm 37.87$ \\
\hline TSH(mIU/L) & $0.06 \pm 0.25$ & $0.004 \pm 0.003^{\#}$ & $0.06 \pm 0.36$ & $0.01 \pm 0.017$ \\
\hline TPOAb(IU/mL) & $859.05 \pm 575.77$ & $899.25 \pm 550.87$ & $835.48 \pm 562.10$ & $802.49 \pm 574.35$ \\
\hline TRAb(IU/L) & $15.76 \pm 12.15$ & $15.18 \pm 12.55$ & $16.97 \pm 12.11$ & $18.48 \pm 13.00$ \\
\hline${ }^{131}$ I dose(mCi) & $8.14 \pm 2.32$ & $9.59 \pm 2.86$ & $8.74 \pm 3.53$ & $7.84 \pm 2.86$ \\
\hline $24 \mathrm{~h}$ maximal ${ }^{131} \mathrm{I}$ uptake rate(\%) & $73.89 \pm 9.55$ & $68.91 \pm 10.09$ & $72.24 \pm 12.92$ & $75.85 \pm 12.42$ \\
\hline
\end{tabular}

Data are expressed as mean \pm standard deviation according to the distribution. ${ }^{*} p<0.05$ represents 7-12 months group versus $13-60$ months group

${ }^{\#} p<0.05$ represents $7-12$ months group versus the other three groups

biological properties of TRAb, with TRAb bioactivity being measured in 20 controls, 22 onset GD patients without radioiodine therapy and 84 patients treated with radioiodine therapy (1-6 months group $[n=20]$, 7-12 months group $[n=19], 13-60$ months group $[n=29],>60$ months group $[n=16]$ ), who were randomly chosen with different TRAb levels to ensure the highest coverage. Most patients in the onset GD group had detectable TSAbs $(82 \%, 18 / 22)$, whereas only $4.5 \%$ of patients had TBAbs $(1 / 22)$. The proportion of patients with TSAbs after 1-6 months from ${ }^{131}$ I therapy decreased significantly, but the proportion of those with TBAbs increased (20\% vs. $55 \%$ ). $10 \%$ of patients showed both TSAbs and TBAbs. The proportion of patients with TSAbs after 7-12 months from ${ }^{131}$ I therapy increased $(63 \%, 12 / 19)$; the proportion with TBAbs increased slightly compared with those after 1-6 months from ${ }^{131}$ I therapy $(58 \%, 11 /$ 19). However, the proportion of patients showing both TSAbs and TBAbs increased (32\%, 6/19). Among those after $13-60$ months from ${ }^{131}$ I therapy, the proportion with TSAbs decreased (24\%, 7/29), and $7 \%$ of patients showed TSAbs and TBABs simultaneously. Meanwhile, the proportion of TBAbpositive patients was increased in this group (65\%, 19/29). The rate of TSAb-positive patients after over 60 months from receiving ${ }^{131} \mathrm{I}$ therapy exhibited a greater decrease than the other groups $(19 \%, 3 / 16)$, and the proportion of patients with TBAbs was $56 \%$ (9/16). (Figure 3A, B). Levels of TSAb and TBAb

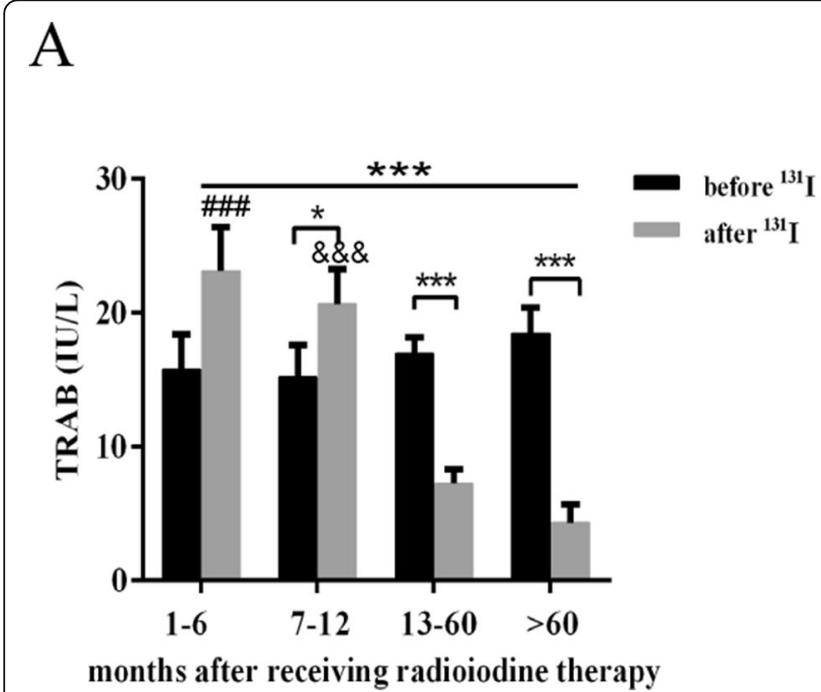

B

Fig. 1 Time course changes in antibodies after ${ }^{131}$ I therapy. A and $\mathbf{B}$ Show time course changes in TRAb and TPOAb in Graves' disease patients before and after ${ }^{131}$ I therapy. ${ }^{*}$ denotes $p<0.05,{ }^{* * *}$ denotes $p<0.001,{ }^{\# \# \#} p<0.001$ represents the $1-6$ months group versus $13-60$ months group and $>60$ months group, ${ }^{\text {\&\&\& }} p<0.001$ represents the 7-12 months group versus $13-60$ months group and $>60$ months group, ${ }^{\$ \$} p<0.01$ represents the 13-60 months group versus $>60$ months group 
Table 3 Changes of TRAb and TPOAb at different time after 131I treatment

\begin{tabular}{|c|c|c|c|c|c|c|}
\hline & \multicolumn{2}{|c|}{ GD patients with decreased antibodies } & \multicolumn{2}{|c|}{ GD patients with increased antibodies } & \multicolumn{2}{|c|}{ GD patients with unchanged antibodies } \\
\hline & $\operatorname{TRAb}^{* * *}$ & TPOAb $^{\# \# \#}$ & TRAb & TPOAb & TRAb & TPOAb \\
\hline $1-6 m$ & $18 \%(4 / 22)$ & $0(0 / 22)$ & $73 \%(16 / 22)$ & $27 \%(6 / 22)$ & $9 \%(2 / 22)$ & $73 \%(16 / 22)$ \\
\hline $7-12 m$ & $36 \%(10 / 28)$ & $7 \%(2 / 28)$ & $53 \%(15 / 28)$ & $29 \%(8 / 28)$ & $11 \%(3 / 28)$ & $64 \%(18 / 28)$ \\
\hline $13-60 m$ & $79 \%(83 / 105)$ & $38 \%(40 / 105)$ & $19 \%(20 / 105)$ & $15 \%(16 / 105)$ & $2 \%(2 / 105)$ & $47 \%(49 / 105)$ \\
\hline$>60 \mathrm{~m}$ & $88 \%(42 / 48)$ & $65 \%(31 / 48)$ & $2 \%(1 / 48)$ & $12 \%(6 / 48)$ & $10 \%(5 / 48)$ & $23 \%(11 / 48)$ \\
\hline
\end{tabular}

TRAb or TPOAb increased: TRAb of ${ }^{131}$ I therapy after/before $\geq 1.1$

TRAb or TPOAb decreased: TRAb of 131 I therapy before/after $\geq 1.1$

${ }^{* * *} p<0.001$ represents changes of TRAb comes from Trend Test

$\# \#$ \# $<0.001$ represents changes of TPOAb comes from Trend Test

were $58-143 \%$ and $-18-15 \%$, respectively. We defined above the mean +2 SD as positive (TSAB $\geq 150 \%$, TBAB $\geq 17 \%$ ).

\section{Correlation of TSAb/TBAb and thyroid function after ${ }^{131}$ I therapy}

We further investigated the correlation between thyroid function and TSAb/TBAb in GD patients after ${ }^{131} \mathrm{I}$ therapy. The proportions of TSAb positivity in patients with hyperthyroidism, euthyroidism and hypothyroidism were 40.7\% (11/27), 37.5\% (9/24) and 20.5\% (7/34), respectively. Although the proportion of TSAb-positive GD patients with hyperthyroidism after ${ }^{131}$ I therapy was slightly higher, no significant differences were found among the groups (Fig. 4A). The proportions of TBAb-positive GD patients after ${ }^{131}$ I therapy with hyperthyroidism, euthyroidism and hypothyroidism were 37\% (10/27), 66.7\% (16/24) and $73.5 \%$ (25/34), respectively. Interestingly, the proportion of TBAb-positive GD patients with hypothyroidism or euthyroidism after ${ }^{131} \mathrm{I}$ therapy was higher than that in GD patients with hyperthyroidism $(73.5 \%$ vs. $37 \%, p<$ $0.001 ; 66.7 \%$ vs. $37 \%, p<0.01$, respectively) (Fig. 4B).

\section{Discussion}

GD and HT are two main types of AITDs with different physiopathologies. TRAb and TPOAb are characterized autoantibodies in GD [22]. TRAbs exhibit three different biological properties, including TSAbs, TBAbs and neutral TSH receptor antibodies. TSAbs are responsible for GD hyperthyroidism, whereas TBAbs are sometimes responsible for a pattern of hypothyroidism [23]. ${ }^{131}$ I therapy is increasingly used as a first-line treatment for hyperthyroidism in GD [20], and previous studies have reported that patients with GD treated with a dose of ${ }^{131}$ I can develop hypothyroidism. Although the traditional view considers GD and HT to be two separate diseases, the present view is that these conditions may be opposite ends of the spectrum of one disease. Indeed, a few researchers have reported a sequential phenotypic conversion from GD to HT or vice versa [24-26]. The underlying mechanism is not clear but may be determined by the following factors: TSAb and TBAb activity, responsiveness of the thyroid gland to TSAb or TBAb, and changes in the thyroid gland [23]. TSAbs and TBAbs are antibodies against TSHR, but the antigens are different. The uncleaved, single-chain TSHR polypeptide consists of 764 amino acids (including a 21residue signal peptide absent in the mature protein). After expression on the thyrocyte cell surface, TSHR undergoes cleavage within the "hinge" region at two or more sites. Loss of the $\mathrm{C}$-peptide-like region leads to an extracellular A-subunit linked by disulfide bonds to the
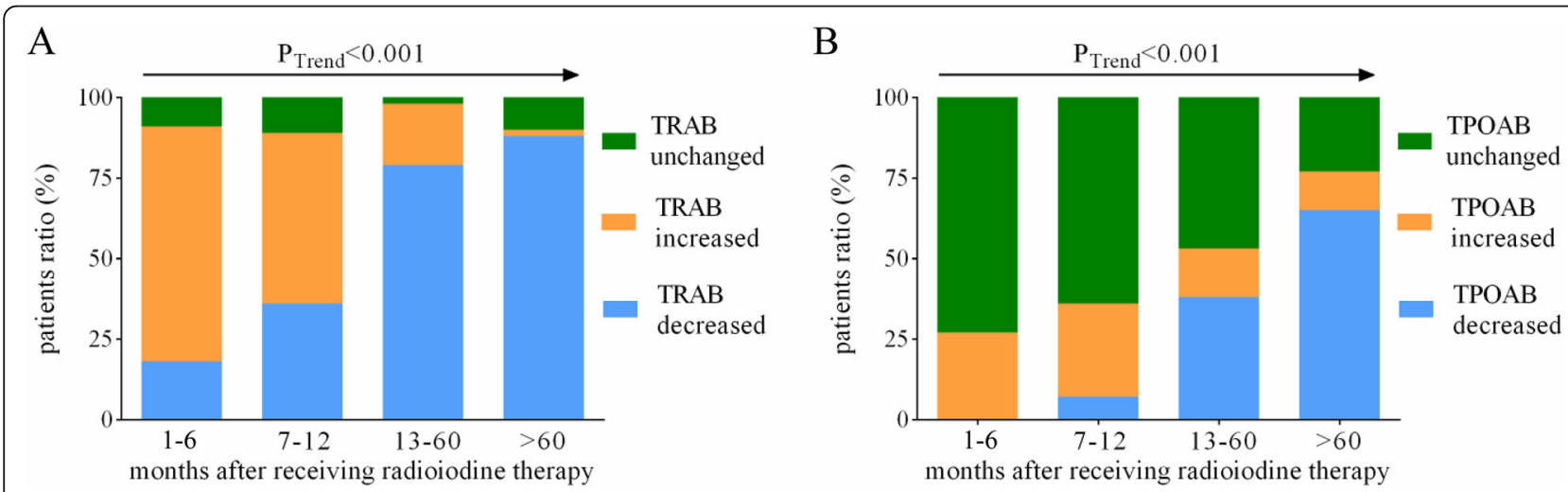

Fig. 2 Changes in TRAb and TPOAb at different times after ${ }^{131} \mathrm{I}$ treatment. This picture shows the time course discrepancy of the GD patient ratio with different TRAb changes (A) and TPOAb changes (B) after RAl therapy. The $p$ value was obtained by the Trend Test 


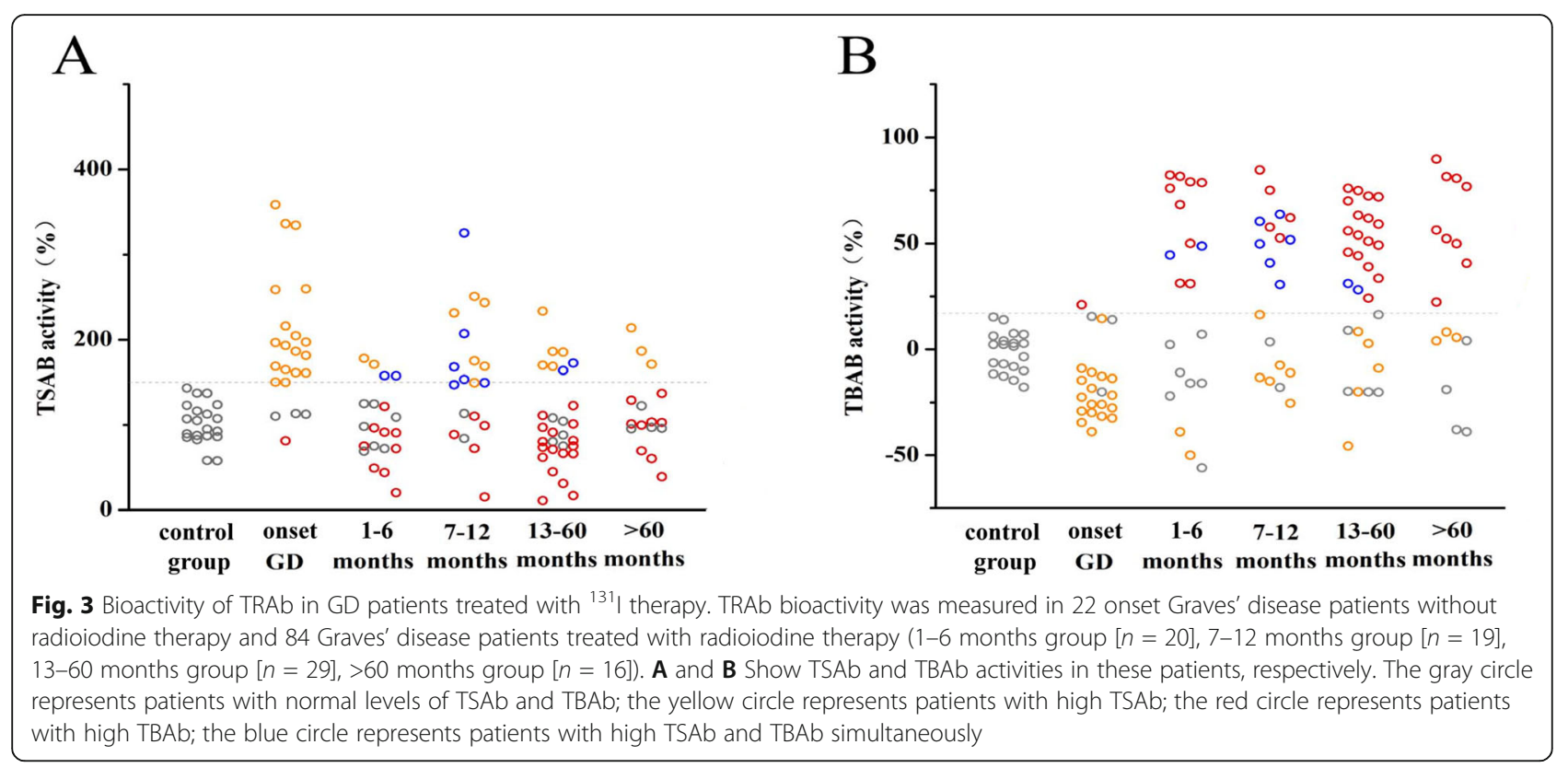

B-subunit, which comprises the remainder of the hinge region, transmembrane, and cytoplasmic tail. Some Asubunits are shed. Substantial evidence suggests that the shed A subunit, rather than the TSH holoreceptor, is more important in the induction or affinity maturation of TSAbs that cause GD $[27,28]$. In contrast, the holoreceptor is a much more potent immunogen for TBAbs. In the present study, we found a period in which TSAbs and TBAbs exist simultaneously in some patients after ${ }^{131}$ I therapy; the proportion of TSAbs decreased while that of TBAbs increased. Therefore, it is reasonable to presume that ${ }^{131}$ I therapy causes thyrocyte damage in GD patients, which can lead to the release of thyroid antigens, including the holoreceptor of TSHR and other antigens, further triggering the autoimmune response to induce the production of TBAbs and other autoantibodies against thyroid antigens [28]. Interestingly, McLachlan et al. found that by depletion of $\mathrm{T}$ regulatory cells (Treg) with anti-CD25 before TSHR-Ad immunization, the immunization with TSHR-Ad induced extensive thyroid lymphocytic infiltration and hypothyroidism in human TSHR A subunit-expressing transgenic mice

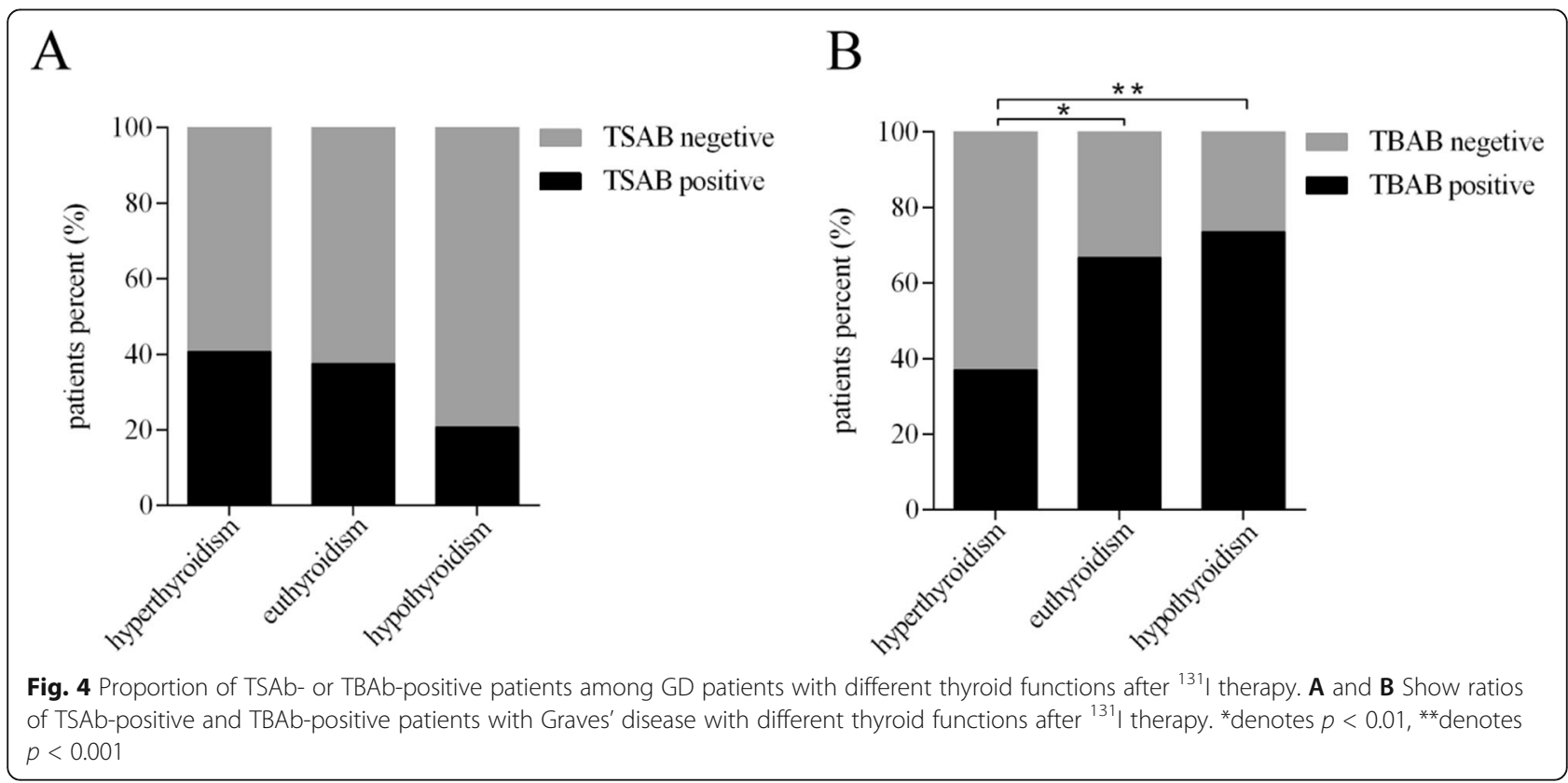


(named Lo-expressor TSHR A subunit transgenic mice) but not in these mice without Treg depletion. Moreover, autoantibodies against mTPO and mTG were also induced by TSHR-Ad immunization in Lo-expressor TSHR A subunit transgenic mice after depletion of Treg with anti-CD25, similar to our findings in GD patients after RAI therapy. Given that the mice had thyroid lymphocytic infiltration and hypothyroidism, it will be interesting to investigate the biological characterization of TRAb in the future in Lo-expressor TSHR A-subunit transgenic mice depleted of Treg cells with anti-CD25 and immunized with TSHR-Ad [29]. Takasu et al. found that all of the HT patients with hypothyroidism $(n=43)$ exhibited TBAb positivity in European patients [30]. A previous study reported that HT patients could spontaneously recover from hypothyroidism, with TBAb disappearance [31]. Therefore, the hypothyroidism in these patients may be attributed to TBAb. The data suggested that the increase of TBAb might play a role in the process of hypothyroidism in GD patients after ${ }^{131} \mathrm{I}$ therapy.

In addition to genetic and environmental factors, treatment for hyperthyroidism also affects GD activity [32, 33]. A prospective randomized study compared antithyroid drugs, thyroidectomy and radioiodine and found that the two former treatments resulted in a continuous decrease in TRAb but that radioiodine resulted in an increase in TRAb after 3 months [34]. Lindgren et al. compared TRAb, TPOAb and TGAb before and 3 months after ${ }^{131} \mathrm{I}$ therapy and found that radioiodine elicited an increase in these antibodies, though not in all GD patients [35]. In the present study, most patients exhibited increases in TRAb in the first year from ${ }^{131}$ I therapy, and most exhibited decreases in TRAb after 1 year from therapy. Some patients showed increases in TPOAb during the first year from therapy, but the proportion was much lower than that of patients with increased TRAb. Further investigation revealed a decrease in TSAbpositive patients in the 1-6 month group and an increase in TSAb-positive patients in the 7-12-month group. After one year, the TSAbs decreased gradually. However, TBAb was elicited after ${ }^{131}$ I therapy, and the level increased in the first 5 years. After one year from radioiodine treatment, most patients were TBAb positive. Following ${ }^{131} \mathrm{I}$ therapy, thyroid secretion declined gradually over weeks to months. Approximately $50-70 \%$ of patients become euthyroid within 6 to 8 weeks, with a concomitant marked reduction in thyroid size [36]. In general, when receiving a calculated dose or a fixed dose in the 10 to $15 \mathrm{mCi}(370-555 \mathrm{MBq})$ range, $80-90 \%$ of patients ultimately become euthyroid or hypothyroid after one dose of ${ }^{131}$ I; 10 to $20 \%$ require a second dose, and only rare need an additional dose [37]. Our study found that TSAb positivity was more likely to be present in those patients after 7-12 months from radioiodine therapy. Therefore, we suggest that the first treatment dose of radioiodine for GD patients should not be high and that slightly higher thyroid function may be tolerated in patients in the first year from receiving ${ }^{131}$ I treatment. For patients exhibiting high T4 after the first ${ }^{131} \mathrm{I}$ dose, anti-thyroid drugs may be more beneficial than the second dose of ${ }^{131} \mathrm{I}$ in the first year from ${ }^{131}$ I treatment. Notably, we observed a positive relationship between the ${ }^{131}$ I dose and development of hypothyroidism within the first year of therapy. However, the incidence of hypothyroidism beyond 1 year was approximately $2-3 \%$ annually and seemed largely independent of the ${ }^{131} \mathrm{I}$ dose. We analyzed this phenomenon, which may be caused by the continuous existence of TBAb, and the underlying mechanism must be further investigated. Although there is no established teratogenic risk with radioactive iodine, it has been suggested that conception should be deferred for at least 4 months after therapy [36]. In fact, previous reports have suggested transplacental passage of TSAbs from mother to fetus as the cause of neonatal thyroid dysfunction [38, 39]. Our data suggest that TSAb levels should be detected in women of childbearing age after 7-12 months from radioiodine treatment to decide the appropriate time to conceive.

\section{Conclusions}

In conclusion, we found that treatment with radioiodine elicited an increase in TSAb and TPOAb in the first year after therapy. As there was a decline after 1 year, the dose of ${ }^{131}$ I should not be high, and TSAb levels should be detected in women of childbearing age after 7-12 months from radioiodine treatment for decision-making regarding conception. Our study detected a trend that after ${ }^{131} \mathrm{I}$ therapy the proportion of patients with both TSAbs and TBAbs first increased and then decreased; the proportion of patients with TBAbs increased, which suggests that the pathogenic mechanisms of the two AITDs may be opposite ends of the spectrum of one disease.

\section{Acknowledgements}

Not Applicable.

\section{Authors' contributions}

Conceptualization, M.D., G.Q.G. and H.D.S.; methodology, Y.F and W.H.D; validation, Y.F., W.H.D.; formal analysis, Y.F. and C.X.Z.; writing-original draft preparation, Y.F; writing - review and editing, M.D. and H.D.S.; supervision, M.D., G.Q.G. and H.D.S.; funding acquisition, S.X.Z. and H.D.S. All authors have read and agreed to the published version of the manuscript.

Funding

This work was supported by the National Natural Science Foundation of China (grants, 81661168016, 81870537, 81770786) and National Key R\&D Program of China (grant, 2017YFC1001801). 


\section{Availability of data and materials}

The datasets used and/or analyzed during this study are available from the corresponding authors on reasonable request.

\section{Declarations}

\section{Ethics approval and consent to participate}

The project was approved by the local ethics committee (the Ninth People's Hospital Affiliated to Shanghai Jiao Tong University School of Medicine) and performed in accordance with the ethical standards of the Declaration of Helsinki (2013 version) and its later amendments or comparable ethical standards. Informed written consent has been obtained from each subject after full explanation of the purpose and nature of all procedures used was given.

\section{Consent for publication}

Not Applicable.

\section{Competing interests}

These authors declare that they have no competing interests.

Received: 13 June 2021 Accepted: 18 November 2021

Published online: 30 November 2021

\section{References}

1. Antonelli A, Ferrari SM, Corrado A, Di Domenicantonio A, Fallahi P. Autoimmune thyroid disorders. Autoimmun Rev. 2015;14(2):174-80.

2. Brand OJ, Gough SCL. Genetics of thyroid autoimmunity and the role of the TSHR. Mol Cell Endocrinol. 2010;322(1-2):135-43.

3. Mizuma $T$, Watanabe $M$, Inoue $N$, Arakawa $Y$, Tomari $S$, Hidaka $Y$, Iwatani $Y$. Association of the polymorphisms in the gene encoding thyroglobulin with the development and prognosis of autoimmune thyroid disease. Autoimmunity. 2017;50(6):386-92

4. Tomari S, Watanabe M, Inoue N, Mizuma T, Yamanaka C, Hidaka Y, Iwatani $Y$. The polymorphisms in the thyroid peroxidase gene were associated with the development of autoimmune thyroid disease and the serum levels of anti-thyroid peroxidase antibody. Endocr J. 2017;64(10):1025-32.

5. Zöphel K, Roggenbuck D, Schott M. Clinical review about TRAb assay's history. Autoimmun Rev. 2010;9(10):695-700.

6. Akamizu T. Antithyrotropin receptor antibody: an update. Thyroid. 2001; 11(12):1123-34.

7. Carella C, Mazziotti G, Sorvillo F, Piscopo M, Cioffi M, Pilla P, Nersita R, lorio S, Amato G, Braverman LE, et al. Serum thyrotropin receptor antibodies concentrations in patients with Graves' disease before, at the end of methimazole treatment, and after drug withdrawal: evidence that the activity of thyrotropin receptor antibody and/or thyroid response modify during the observation period. Thyroid. 2006;16(3):295-302.

8. Roggenbuck JJ, Veiczi M, Conrad K, Schierack P, Wunderlich G, Kotzerke J, Roggenbuck D, Zöphel K. A novel third-generation TSH receptor antibody (TRAb) enzyme-linked immunosorbent assay based on a murine monoclonal TSH receptor-binding antibody. Immunol Res. 2018;66(6):76876.

9. Effraimidis G, Wiersinga WM. Mechanisms in endocrinology: autoimmune thyroid disease: old and new players. Eur J Endocrinol. 2014;170(6):R241-52.

10. Aizawa Y, Yoshida K, Kaise N, Fukazawa H, Kiso Y, Sayama N, Hori H, Abe K. The development of transient hypothyroidism after iodine-131 treatment in hyperthyroid patients with Graves' disease: prevalence, mechanism and prognosis. Clin Endocrinol. 1997;46(1):1-5.

11. Husseni $M$. The incidence of hypothyroidism following the radioactive iodine treatment of Graves' disease and the predictive factors influencing its development. World J Nucl Med. 2016;15(1):30-7.

12. Atkinson S, McGregor AM, Kendall-Taylor P, Peterson MM, Smith BR. Effect of radioiodine on stimulatory activity of Graves' immunoglobulins. Clin Endocrinol. 1982;16(6):537-43.

13. Teng CS, Yeung RT, Khoo RK, Alagaratnam TT. A prospective study of the changes in thyrotropin binding inhibitory immunoglobulins in Graves' disease treated by subtotal thyroidectomy or radioactive iodine. J Clin Endocrinol Metab. 1980;50(6):1005-10.

14. Chiovato L, Fiore E, Vitti P, Rocchi R, Rago T, Dokic D, Latrofa F, Mammoli C, Lippi $F$, Ceccarelli $C$, et al. Outcome of thyroid function in Graves' patients treated with radioiodine: role of thyroid-stimulating and thyrotropin- blocking antibodies and of radioiodine-induced thyroid damage. J Clin Endocrinol Metab. 1998:83(1):40-6.

15. Endocrinology Branch of the Chinese Medical Association, Preparation group of the Guidelines for the Diagnosis and Treatment of Thyroid Diseases in China. Chinese guide for diagnosis and treatment of thyroid diseases-laboratory and auxiliary examination of thyroid diseases. Zhonghua Nei Ke Za Zhi. 2007;46(08):697-702 Chinese.

16. Endocrinology Branch of the Chinese Medical Association, Preparation group of the Guidelines for the Diagnosis and Treatment of Thyroid Diseases in China. Chinese guidelines for diagnosis and treatment of thyroid diseases - hyperthyroidism. Zhonghua Nei Ke Za Zhi. 2007;46(10):876-82 Chinese.

17. Chu X, Pan CM, Zhao SX, Liang J, Gao GQ, Zhang XM, Yuan GY, Li CG, Xue $L Q$, Shen $M$, et al. A genome-wide association study identifies two new risk loci for Graves' disease. Nat Genet. 2011:43(9):897-901.

18. Liu W, Zhang QY, Yuan FF, Wang HN, Zhang LL, Ma YR, Ye XP, Zhang MM, Song ZY, Li SX, et al. A dense mapping study of six European AITD susceptibility regions in a large Chinese Han Cohort of Graves' disease. Clin Endocrinol (Oxf). 2018:89(6):840-8.

19. Zhao SX, Xue LQ, Liu W, Gu ZH, Pan CM, Yang SY, Zhan M, Wang HN, Liang J, Gao GQ, Zhang XM, et al. Robust evidence for five new Graves' disease risk loci from a staged genome-wide association analysis. Hum Mol Genet. 2013;22(16):3347-62.

20. Dong Q, Liu X, Wang F, Xu Y, Liang C, Du W, Gao G. Dynamic changes of TRAb and TPOAb after radioiodine therapy in Graves' disease. Acta Endocrinol (Buchar). 2017;13(1):72-6.

21. Fang $Y$, Sun F, Zhang R-J, Zhang C-R, Yan C-Y, Zhou Z, Zhang Q-Y, Li L, Ying Y-X, Zhao S-X, et al. Mutation screening of the TSHR gene in 220 Chinese patients with congenital hypothyroidism. Clin Chim Acta. 2019:497:147-52

22. Guilhem I, Massart C, Poirier J-Y, Maugendre D. Differential evolution of thyroid peroxidase and thyrotropin receptor antibodies in Graves' disease: thyroid peroxidase antibody activity reverts to pretreatment level after carbimazole withdrawal. Thyroid. 2006;16(10):1041-5.

23. Takasu N, Yoshimura Noh J. Hashimoto's thyroiditis: TGAb, TPOAb, TRAb and recovery from hypothyroidism. Expert Rev Clin Immunol. 2008;4(2):22137.

24. Umar H, Muallima N, Adam JMF, Sanusi H. Hashimoto's thyroiditis following Graves' disease. Acta Med Indones. 2010;42(1):31-5.

25. Champion B, Gopinath B, Ma G, El-Kaissi S, Wall JR. Conversion to Graves' hyperthyroidism in a patient with hypothyroidism due to Hashimoto's thyroiditis documented by real-time thyroid ultrasonography. Thyroid. 2008; 18(10):1135-7.

26. Gonzalez-Aguilera B, Betea D, Lutteri L, Cavalier E, Geenen V, Beckers A, Valdes-Socin H. Conversion to Graves disease from Hashimoto thyroiditis: a study of 24 patients. Arch Endocrinol Metab. 2018;62(6):609-14.

27. Chen CR, Pichurin P, Nagayama Y, Latrofa F, Rapoport B, McLachlan SM. The thyrotropin receptor autoantigen in Graves disease is the culprit as well as the victim. J Clin Invest. 2003;111(12):1897-904.

28. Zhang QY, Liu W, Li L, Du WH, Zuo CL, Ye XP, Zhou Z, Yuan FF, Ma YR, Sun $F$, et al. Genetic study in a large cohort supported different pathogenesis of Graves' disease and Hashimoto's hypothyroidism. J Clin Endocrinol Metab. 2020;105(7):e2600-8

29. McLachlan SM, Nagayama Y, Pichurin PN, Mizutori Y, Chen CR, Misharin A, Aliesky HA, Rapoport B. The link between Graves' disease and Hashimoto's thyroiditis: a role for regulatory T cells. Endocrinology. 2007;148(2):5724-33.

30. Takasu N, Yamashiro K, Ochi Y, Sato Y, Nagata A, Komiya I, Yoshimura H. TSBAb (TSH-stimulation blocking antibody) and TSAb (thyroid stimulating antibody) in TSBAb-positive patients with hypothyroidism and Graves' patients with hyperthyroidism. Horm Metab Res. 2001:33(4):232-7.

31. Takasu N, Yamada T, Takasu M, Komiya I, Nagasawa Y, Asawa T, Shinoda T, Aizawa T, Koizumi Y. Disappearance of thyrotropin-blocking antibodies and spontaneous recovery from hypothyroidism in autoimmune thyroiditis. $\mathrm{N}$ Engl J Med. 1992;326(8):513-8.

32. Codaccioni JL, Orgiazzi J, Blanc P, Pugeat M, Roulier R, Carayon P. Lasting remissions in patients treated for Graves' hyperthyroidism with propranolol alone: a pattern of spontaneous evolution of the disease. J Clin Endocrinol Metab. 1988;67(4):656-62.

33. Davies TF, Ando T, Lin R-Y, Tomer $Y$, Latif R. Thyrotropin receptor-associated diseases: from adenomata to Graves disease. J Clin Invest. 2005;115(8):1972-83.

34. Laurberg P, Wallin G, Tallstedt L, Abraham-Nordling M, Lundell G, Tørring O. TSH-receptor autoimmunity in Graves' disease after therapy with anti- 
thyroid drugs, surgery, or radioiodine: a 5-year prospective randomized study. Eur J Endocrinol. 2008;158(1):69-75.

35. Lindgren O, Asp P, Sundlöv A, Tennvall J, Shahida B, Planck T, Åsman P, Lantz $M$. The effect of radioiodine treatment on TRAb, anti-TPO, and anti-TG in Graves' disease. Eur Thyroid J. 2019;8(2):64-9.

36. Weetman AP. Graves' disease. N Engl J Med. 2000;343(17):1236-48.

37. Hegedüs L. Treatment of Graves' hyperthyroidism: evidence-based and emerging modalities. Endocrinol Metab Clin North Am. 2009;38(2):355-71.

38. McKenzie JM, Zakarija M. Fetal and neonatal hyperthyroidism and hypothyroidism due to maternal TSH receptor antibodies. Thyroid. 1992;2(2): 155-9.

39. Grulet H, Barraud S, Chikh K, Souchon PF, Claris O, Bouvier R, Trouillas J, Gabriel R, Bory JP, Schvartz C, et al. Three consecutive pregnancies in a patient with chronic autoimmune thyroid disease associated with hypothyroidism and extremely high levels of anti-thyrotropin receptor antibodies. Thyroid. 2019;29(5):743-7.

\section{Publisher's Note}

Springer Nature remains neutral with regard to jurisdictional claims in published maps and institutional affiliations.

Ready to submit your research? Choose BMC and benefit from:

- fast, convenient online submission

- thorough peer review by experienced researchers in your field

- rapid publication on acceptance

- support for research data, including large and complex data types

- gold Open Access which fosters wider collaboration and increased citations

- maximum visibility for your research: over $100 \mathrm{M}$ website views per year

At BMC, research is always in progress.

Learn more biomedcentral.com/submissions 